\title{
Health-care costing in the Netherlands
}

\author{
R Meijer ${ }^{*}, H$ Rutgers \\ From 26th Patient Classification Systems International (PCSI) Working Conference \\ Munich, Germany. 15-18 September 2010
}

\section{Introduction}

With the introduction of the DBC system in 2005, the funding of Dutch health care gradually began to change. The DBC system is replacing the current system of position-based budgeting (block grant) of providers and the lump-sum funding of medical specialists. In 2005, two segments were introduced for somatic health care.

An A-segment, with fixed national tariffs for health providers and medical specialists, is used for billing only. Block grants still exist for actual costing. In the B-segment, provider prices are set based on local negotiations between provider and insurer, combined with fixed national tariffs for medical specialists.

With the B-segment, market principles were introduced in the Dutch health-care system. Naturally there was, and still is, a strong political involvement in the size and composition of the B-segment which, at this moment, comprises about 34 percent of annual hospital turnover.

In 2008, lump-sum funding for medical specialists was replaced with a remuneration system based on work load and a fixed hourly rate. In 2011, the next step toward performance funding is planned. Block grants for providers in the A-segment, including mental health care, should be replaced by actual costing based on DBC tariffs. However, this was deferred to at least 2012 due to the current political situation. In the long run, the B-segment will comprise about 70 percent of annual hospital turnover.

\section{Methods}

The Dutch case-mix office (DBC-Onderhoud) has an import role in calculating national tariffs. To do so, DBC-Onderhoud (DBC-O) needs different kinds of information from different sources as building blocks. There are three cost-components for each DBC: a separate cost-component for the total hospital costs of a

BC-Onderhoud, Utrecht, Netherlands
DBC; a cost for the main medical specialist; and costs for all supporting medical specialists that are involved in treating the patient.

Every medical association estimates the time needed for each DBC to be produced by their specialty. Matched with the total capacity in the Netherlands, this determines the 'work load' per DBC. The Dutch health authority determines the hourly rate for the medical specialists. Medical associations that represent supporting specialties estimate the time needed per care activity to be produced by their specialty. Matched with the total capacity in the Netherlands, the 'work load' per care activity is determined.

Healthcare providers supply production information to DIS (DBC Information System). DIS information from a one-year period is being used as a basis for constructing DBC profiles - a description of the frequency of the different care activities per DBC. DBC-O collects costinformation from providers. Providers are arranged in groups primarily based on the type of provider.

With the collected information, DBC-O calculates prices for each of the three cost components. Based on these prices, the Dutch health authority $(\mathrm{NZa})$ determines tariffs for all components per DBC for the A-segment. Due to market demands and the performance of the health-care system, NZa may decide to use its formal powers as the market regulator and deviate from prices calculated by DBC-O to determine tariffs.

\section{Results}

The costing model described above shows how tariffs are calculated in theory. In practice, there are certain barriers that make it harder to calculate 'proper' tariffs. The first barrier is voluntary supply of cost-information. A sample of providers from each of the previously mentioned groups supplies cost information on a voluntary basis every year. Up until now, both the size and composition of the sample for each of the provider groups differ from year to year. 
The second barrier is the lack of a statistical basis for defining groups, group size and composition. A framework is being developed by $\mathrm{NZa}$ and $\mathrm{DBC}-\mathrm{O}$ to create this basis. Different allocation rules for both somatic and mental health care create another barrier. The fourth and last barrier concerns the quality of the production information supplied to DIS. Although supply has been obligated since 2005, a part of the production information is incorrect.

\section{Conclusions}

The transition toward performance funding places increasing demands on the costing model and the quality of the underlying cost and production information. Allocation principles are renewed. Possibly, elements of the activity-based costing method will be introduced. Also, capital costs will be incorporated. The health authority will most likely decide to obligate supply of cost-information. This will improve statistical quality of cost information in terms of representation, reliability and accuracy, and thus contribute to a better costing model.

Increasingly, complex data processing is needed for production information to meet existing needs. Improving the quality of production information in terms of completeness, timeliness and accuracy is essential. DIS introduced feedback information to suppliers to enforce quality improvements. DBC-O also organizes learning sessions to share its costing model outcome with providers.

Published: 6 October 2010

doi:10.1186/1472-6963-10-S2-A20

Cite this article as: Meijer and Rutgers: Health-care costing in the

Netherlands. BMC Health Services Research 2010 10(Suppl 2):A20.
Submit your next manuscript to BioMed Central and take full advantage of:

- Convenient online submission

- Thorough peer review

- No space constraints or color figure charges

- Immediate publication on acceptance

- Inclusion in PubMed, CAS, Scopus and Google Scholar

- Research which is freely available for redistribution

Submit your manuscript at www biomedcentral com/submit 